Cahiers $d u$ MONDE RUSSE

\section{Cahiers du monde russe}

Russie - Empire russe - Union soviétique et États indépendants

$46 / 4 \mid 2005$

L'invention d'une politique humanitaire

\title{
Valters Nollendorfs, Erwin Oberländer, eds., The Hidden and Forbidden History of Latvia under Soviet and Nazi Occupations
}

Nicolas Werth

\section{(2) OpenEdition \\ 12 Journals}

\section{Édition électronique}

URL : https://journals.openedition.org/monderusse/6629

DOI : 10.4000/monderusse.6629

ISSN : $1777-5388$

Éditeur

Éditions de l'EHESS

Édition imprimée

Date de publication : 1 décembre 2005

Pagination : 929-931

ISBN : 2-7132-2057-2

ISSN : $1252-6576$

Référence électronique

Nicolas Werth, « Valters Nollendorfs, Erwin Oberländer, eds., The Hidden and Forbidden History of Latvia under Soviet and Nazi Occupations », Cahiers du monde russe [En ligne], 46/4 | 2005, mis en ligne le 29 juin 2009, consulté le 04 septembre 2022. URL : http://journals.openedition.org/ monderusse/6629; DOI : https://doi.org/10.4000/monderusse.6629

Ce document a été généré automatiquement le 4 septembre 2022.

Tous droits réservés 


\title{
Valters Nollendorfs, Erwin Oberländer, eds., The Hidden and Forbidden History of Latvia under Soviet and Nazi Occupations
}

\author{
Nicolas Werth
}

\section{RÉFÉRENCE}

Valters NOLLENDORFS, Erwin OBERLÄNDER, eds., The Hidden and Forbidden History of Latvia under Soviet and Nazi Occupations, 1940-1991. Selected Research of the Commission of the Historians of Latvia. Riga : Institute of the History of Latvia, 2005, 383 p. (Symposium of the Commission of the Historians of Latvia, 14)

1 Ce volume d'articles, publié sous l'égide de la Commission internationale d'historiens mise en place par le gouvernement de la République de Lettonie en 1998, aborde tout un ensemble de questions «sensibles" relatives aux deux grandes occupations, nazie et soviétique, qui ont marqué l'histoire de ce pays balte au $\mathrm{xx}^{\mathrm{e}}$ siècle. Quatorzième de la série, ce volume s'inscrit dans un ensemble déjà fort conséquent de publications encore malheureusement largement méconnues en Occident et notamment en France.

2 Les apports de ce volume sont nombreux, tout particulièrement en ce qui concerne les deux parties consacrées à l'occupation nazie et à la question de l'Holocauste en Lettonie. Les deux parties consacrées aux occupations soviétiques, celle, brève, de 1940-1941, et celle, beaucoup plus longue, de 1944 à 1991, sont en revanche plus convenues. Il est vrai que la question de la soviétisation des pays baltes (surtout dans ses aspects répressifs) a commencé à être, depuis quelques années, bien explorée par un certain nombre d'historiens russes. On connaît assez bien aujourd'hui, grâce en particulier aux historiens proches de l'association Memorial, le déroulement des grandes déportations de juin 1941 et de mars 1949. Sur ces événements, les articles de Rudite Viksne et de Janis Riekstins 
confirment, sur la base d'archives différentes de celles consultées par leurs collègues russes, des faits et des chiffres déjà connus. Peut-être trop rapide, la belle synthèse de Heinrihs Strods, sur la soviétisation de la Lettonie dans les années d'après-guerre, clarifie utilement les trois grandes étapes de ce processus: 1944-1946 - établissement des structures politiques, administratives et militaires; 1947-1950 - la collectivisation permet le contrôle du "pays profond", pour l'essentiel rural, là où l'opposition à la soviétisation est la plus forte; enfin, à partir de 1950, c'est l'industrie lettonne qui est "mise au service» du développement industriel soviétique, par un processus d'intégration économique. Les articles de synthèse (parmi lesquels on citera aussi l'autre article de Strods, consacré au phénomène de la résistance à la soviétisation, ou celui de Daina Bleiere sur la colonisation russe) sont d'autant plus utiles qu'ils présentent systématiquement un état de l'historiographie -communiste, exilée, " postsoviétique »- sur la question.

3 Toutefois, les articles les plus intéressants sont ceux qui s'attaquent aux questions les plus délicates pour la mémoire nationale, en particulier celle de la collaboration avec l'occupant nazi ou la participation des Lettons à l'Holocauste. Plusieurs études analysent, notamment du point de vue de la micro-histoire, ce qui s'est passé durant les quelques jours cruciaux (fin juin-début juillet 1941) de « l'interrègne », entre le départ des troupes soviétiques et l'arrivée de la Wehrmacht. Quelle a été l'ampleur, durant ces jours parfois même ces heures, cruciales -, des pogroms commis à l'instigation de comités locaux et impliquant la population locale? Comment se sont comportés alors, dans les bourgs et les petites villes, les "voisins " ? Particulièrement remarquables à cet égard sont les articles de Dzintars Erglis («A Few Episodes of the Holocaust in Krustpils: A Microcosm of the Holocaust in Occupied Latvia») et de Juris Pavlovics («Change of Occupation Powers in Latvia in Summer 1941: The Experience of Small Communities »). Si des pogroms ont bien eu lieu avant l'arrivée des troupes allemandes, c'est l'arrivée de celles-ci qui démultiplie les massacres. D'emblée, les autorités d'occupation assignent aux " unités d'autodéfense » lettonnes la tâche de traquer l'ensemble de la population juive, de la regrouper, de la convoyer vers les lieux de massacre de masse, la mise à mort étant, en général, effectuée par les Allemands eux-mêmes, les unités les plus diverses (et non pas les seuls Einsatzgruppen) étant directement impliquées dans le massacre. Karlis Kangeris analyse en détail la formation, le développement, les modes de recrutement et la sociologie des "unités fermées» de la police lettonne, les Lettische Schutzmannschafts-Bataillone, au total 48 bataillons, soit 15000 hommes, chargés de traquer les Juifs en Lettonie. Autre formation passée au crible de la recherche par Inesis Feldmanis, la fameuse Légion lettonne de la Waffen-SS. L'auteur replace, fort à propos, l'histoire de cette légion dans l'ensemble des unités non allemandes de la Waffen SS, rappelant qu'en 1944, 57 \% des 900000 SS n'étaient pas des Allemands. Particulièrement éclairante est aussi l'étude consacrée, par Rudite Viksne, au sinistre Commando Arajs, à partir des sources soviétiques conservées aux archives du KGB. L'analyse des 352 dossiers de membres du commando jugés, entre 1944 et 1967, par les tribunaux d'exception soviétiques, permet de faire une belle étude prosopographique. Il en ressort un tableau tout en nuances des motivations qui ont amené de jeunes Lettons, issus souvent d'un milieu éduqué, à s'engager dans ces unités spécialisées dans la traque aux «judéobolcheviks».

4 Des études rassemblées dans ce recueil se dégage un tableau mesuré et complexe des engagements et des itinéraires personnels face à deux occupations, de nature et de temporalité très différentes. On constate, à travers cet ouvrage, tout le chemin parcouru 
depuis une quinzaine d'années par les historiens lettons pour se dégager des stéréotypes, assumer les parts d'ombre de l'histoire nationale et analyser avec lucidité le demi-siècle particulièrement tragique qu'ont connu une société et un pays pris en otages par deux systèmes totalitaires. 